\title{
An activity in design for manufacturability - concept generation through vol- ume production in less than three hours
}

\section{Dr. Paul O. Leisher, Rose-Hulman Institute of Technology}

Dr. Paul O. Leisher is an Associate Professor of Physics and Optical Engineering at Rose-Hulman Institute of Technology. Prior to joining Rose-Hulman in 2011, Dr. Leisher served as the Manager of Advanced Technology at nLight Corporation in Vancouver, Washington, where he worked for over four years. He received the B.S. degree in electrical engineering from Bradley University (Peoria, IL) in 2002. He received the M.S. and Ph.D. degrees in electrical and computer engineering from the University of Illinois at Urbana-Champaign in 2004 and 2007, respectively. Dr. Leisher's research interests include the design, fabrication, characterization, and analysis of high power semiconductor lasers and other photonic devices. He has authored more than 160 technical journal articles and conference presentations. Dr. Leisher is a member of SPIE and the IEEE Photonics Society.

\section{Dr. Scott Kirkpatrick, Rose-Hulman Institute of Technology}

Scott Kirkpatrick is an Assistant Professor of Physics and Optical Engineering at Rose-Hulman Institute of Technology. He teaches physics, semiconductor processes, and micro electrical and mechanical systems (MEMS). His research interests include heat engines, magnetron sputtering, and nanomaterial self assembly. His masters thesis work at the University of Nebraska Lincoln focused on reactive sputtering process control. His doctoral dissertation at the University of Nebraska Lincoln investigated High Power Impulse Magnetron Sputtering.

\section{Dr. Richard W. Liptak, Rose-Hulman Institute of Technology \\ Dr. Sergio Granieri, Rose-Hulman Institute of Technology \\ Dr. Robert M. Bunch, Rose-Hulman Institute of Technology}




\section{An activity in design for manufacturability - concept generation through volume production in less than three hours}

\section{Abstract}

Design for manufacturability (DFM) is the practice of engineering products such that they are more easily produced in volume. DFM is traditionally taught by lecture and students are subsequently encouraged to utilize the underlying concepts in their engineering design courses and capstone project. One of the problems with this approach is that the design is rarely taken to volume production, giving students little chance to see firsthand the benefits of employing DFM in their work. To address this, we have developed an in-class activity which allows student teams to design a widget and take it to volume production all within the span of a single threehour laboratory period. We present the implementation of this activity in our optical engineering and engineering physics capstone design course; sample activity materials will also be provided and discussed.

Students are tasked with designing a widget capable of holding a heavy weight at a minimum height off a table. Specifications are provided on the maximum widget size and allowable materials which can be used. The activity is organized as a competition with a goal of maximizing profit - revenue earned per widget less the cost per widget (material costs, development costs, labor, and cost of poor quality). Students are allowed to choose their team size (there are advantages and disadvantages to both small and large teams) and given time to design and prototype. During this phase the groups must also track their development costs (materials) and develop a production plan which ultimately results in a commitment to deliver a specific quantity of widgets. Following the product development phase, all prototypes and leftover materials are scrapped. The activity then moves to the production phase where teams are given exactly 10 minutes to manufacture the widgets and fulfill their commitment. Acceptance testing is performed on a sample of widgets produced by the team. Severe financial penalties are levied if widgets fail testing or if the team fails to deliver a sufficient quantity. The teams calculate their profitability, and the winning team is announced. Following the activity, the students are assigned homework where they must reflect upon the choices made in the design process and what they could have done to improve their outcome relative to the winning team.

We have found this activity to be highly reusable; for example, by simply adjusting the designated costs or earning per widget, a previous winning design can be rendered ineffective given the new constraints. Further, this activity is a pedagogical approach that is not disciplinespecific; we expect that it is well suited for students in all engineering fields. 


\section{Motivation \& Background}

Design for manufacturability (DFM) is the practice of engineering products such that they are more easily produced in volume [1-3]. Nearly $70 \%$ of the cost to manufacture a product is set during product design [4], making the topic of vital importance to teaching engineering design. DFM is traditionally taught by lecture and students are subsequently encouraged to utilize the underlying concepts in their engineering design courses and capstone project. Several institutions have reported on pedagogical improvements to teaching DFM [4-7]. One issue which deserves additional consideration is that students' designs are rarely taken to volume production, giving students little chance to see firsthand the benefits of employing DFM in their work. Providing students with an opportunity to immediately apply concepts in an activity should enhance learning [8]. To address this, we have developed an in-class activity which allows student teams to design a widget and take it to volume production all within the span of a single three-hour laboratory period. Here we present the implementation of this activity in our optical engineering and engineering physics capstone design course.

\section{Activity Description}

Students are tasked with putting their understanding of DFM into practice by designing a product and taking it through development and into volume production all in the span of a single laboratory period. The course instructor assumes the role of the customer. The activity is organized into a competition, with self-selected teams working towards the goal of any product development project - to make money. Performance in the activity is evaluated in two ways total earnings and gross margin, which allows for a larger variation in team strategy (and up to two winning teams). The total earnings and gross margin are calculated based on revenue (which is based on successful delivery of the committed order) and cost of goods sold (which is based on development costs, material costs, and labor costs). For the sake of simplicity, other indirect costs (overhead) are not considered.

The activity schedule is listed below.

1. Quiz (10 minutes) - A short quiz is given which covers the assigned reading from the course textbook [1].

2. Lecture (30 minutes) - A short lecture is presented reviewing the motivation and basic methods of DFM.

3. Overview (5 minutes) - The activity is introduced and the rules are discussed.

4. Development (50 minutes) - Teams split into groups, "purchase" materials, and develop their prototype. At the end of this phase all materials are scrapped, materials order forms are completed and submitted to the instructor. The students commit to a widget rating and total order quantity.

5. Production (10 minutes) - Teams "purchase" additional materials and mass produce their design for delivery.

6. Scoring (15 minutes) - Acceptance testing is performed by the course instructors. Each team tabulates their results and the winning group is announced. 
Students are tasked with designing a widget capable of holding a heavy weight (either one or two five-pound weights) at a minimum height (1.75") off a table. Specifications are provided on the maximum widget size (2.25" x 2.25" x 2.25") and allowable materials (paper, cardstock, \& tape).

Teams of various sizes ( 1 to 5 students) are allowed, providing some additional freedom in the development of an overall strategy. Because the total quantity of various raw materials which can be purchased per team is constrained, and team labor cost is based on the number of students, each group needs to develop a cohesive strategy which takes into account their specific team size. For example, a small team may wish to pursue a design utilizing better quality (but less plentiful) material.

The students are given about one hour to develop their prototype. During this phase each group must also track their development costs (materials) and develop a production plan which ultimately results in a commitment to deliver a specific quantity of widgets. The total amount of material per group is constrained. Designs which rely on too much material per unit are likely to allow for large total revenue. Designs which rely on a single material type do not allow the team to take full advantage of the resources available. Designs which overly complicated cannot be quickly assembled during the production phase. The teams are cautioned to keep development costs low, as the prototype units developed in this phase cannot be used in production. The students are also advised to consider quality. Some teams elect to burn-in their widgets as part of their fabrication process. Burn-in is the process of subjecting components to use, often under elevated conditions, prior to delivery in order to screen out manufacturing defects which lead to early component failure. Figure 1 provides the bill of materials / sales record sheet that the students use to track their development and production costs and revenue.

Manufacturing cost estimation is vital to the DFM process. To reinforce this, students are required to accurately commit to a delivery quantity up-front. If they promise too few, they end up wasting time and resources (the customer will not buy the extras). If too many are promised, the team is penalized for the shortfall (formula shown in Fig. 1); examples are listed below:

- Example 1 - Commit to 20 units, but build 22. Only 20 units are sold to the customer.

- Example 2 - Commit to 20 units, but build 18. A penalty of 2 units is assessed, thus earnings are equivalent to having delivered 16.

- Example 3 - Commit to 20 units, but build 10. A penalty of 10 units is assessed, thus earnings are equivalent to having delivered 0 .

Following the product development phase, all prototypes and leftover materials are scrapped. The activity then moves to the production phase where teams are given exactly 10 minutes to manufacture the widgets and fulfill their commitment. 


\section{Group Members:}

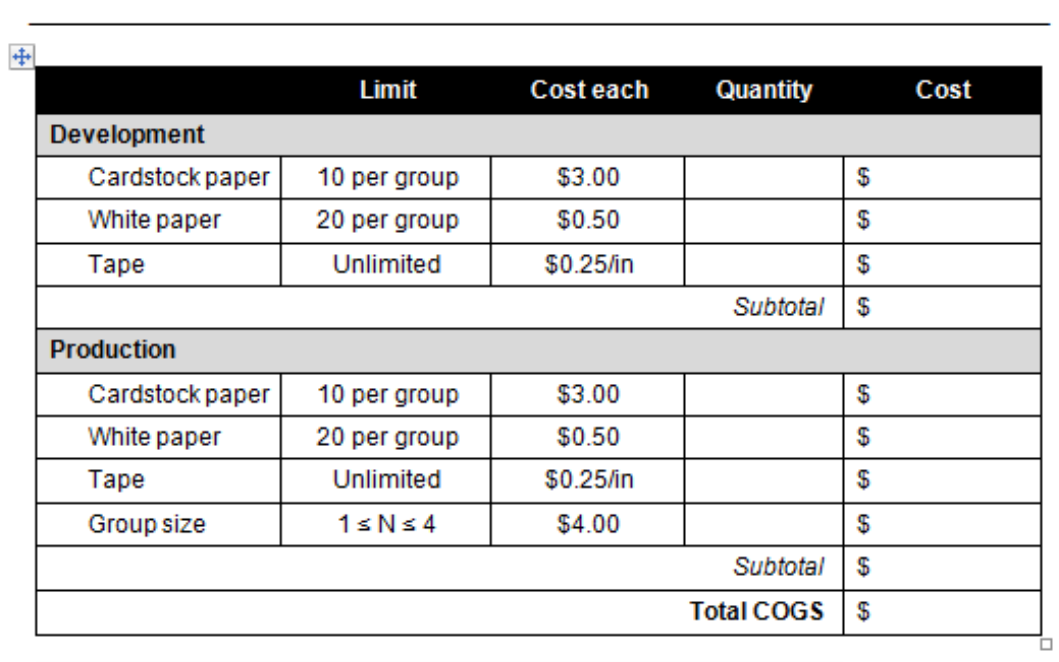

\begin{tabular}{|c|c|c|c|}
\hline Widget rating (Circle one) & 1 block & 2 blocks & Must be \\
\hline BP (base price per unit, circle one) & $\$ 2.00$ & $\$ 3.00$ & \\
\hline O (quantity ordered) & & & Production \\
\hline
\end{tabular}

\begin{tabular}{|c|c|}
\hline \multicolumn{2}{|l|}{ D (quantity delivered) } \\
\hline Acceptance testing & \\
\hline Widget 1 & \\
\hline Widget 2 & \\
\hline Widget 3 & \\
\hline $\mathrm{P}(\%$ passing $)$ & \\
\hline ASP (as sold price per unit, $P \times$ BP) & $\$$ \\
\hline SFP (shortfall penalty, ASP x $(O-D)$ ) & $\$$ \\
\hline Revenue (D x ASP - SFP) & $\$$ \\
\hline Total Earnings & $\$$ \\
\hline Gross Margin & \\
\hline
\end{tabular}

Fig. 1: A bill of materials / sales record sheet is provided to each project team to assist in the tracking of materials, costs, and revenue.

Quality is ensured through acceptance testing, which is performed on a sample of three production widgets per team. The size is checked (as shown in Fig. 2) and functionality is checked by placing weights on top of each widget and sliding a 1.75" measuring standard under each edge (as shown in Fig. 3). In order to best simulate the business environment, severe financial penalties (formula shown in Fig. 1) are levied a widget fails acceptance testing:

- Zero failures - the entire shipment is accepted at full price.

- One failure - the entire shipment is accepted at $66 \%$ price.

- Two failures - the entire shipment is accepted at 33\% price.

- Three failures - the entire shipment is rejected. 

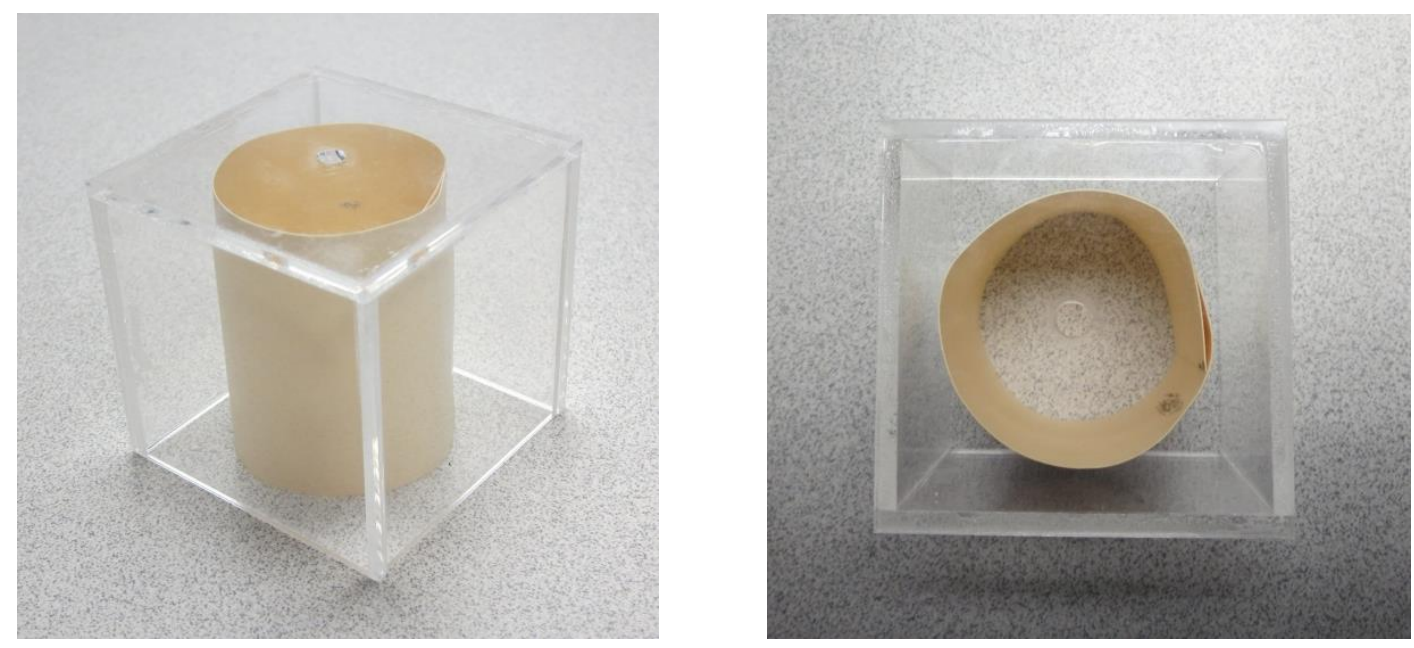

Fig. 2: An acrylic box is used to quickly verify that the widgets meet the dimension specifications.
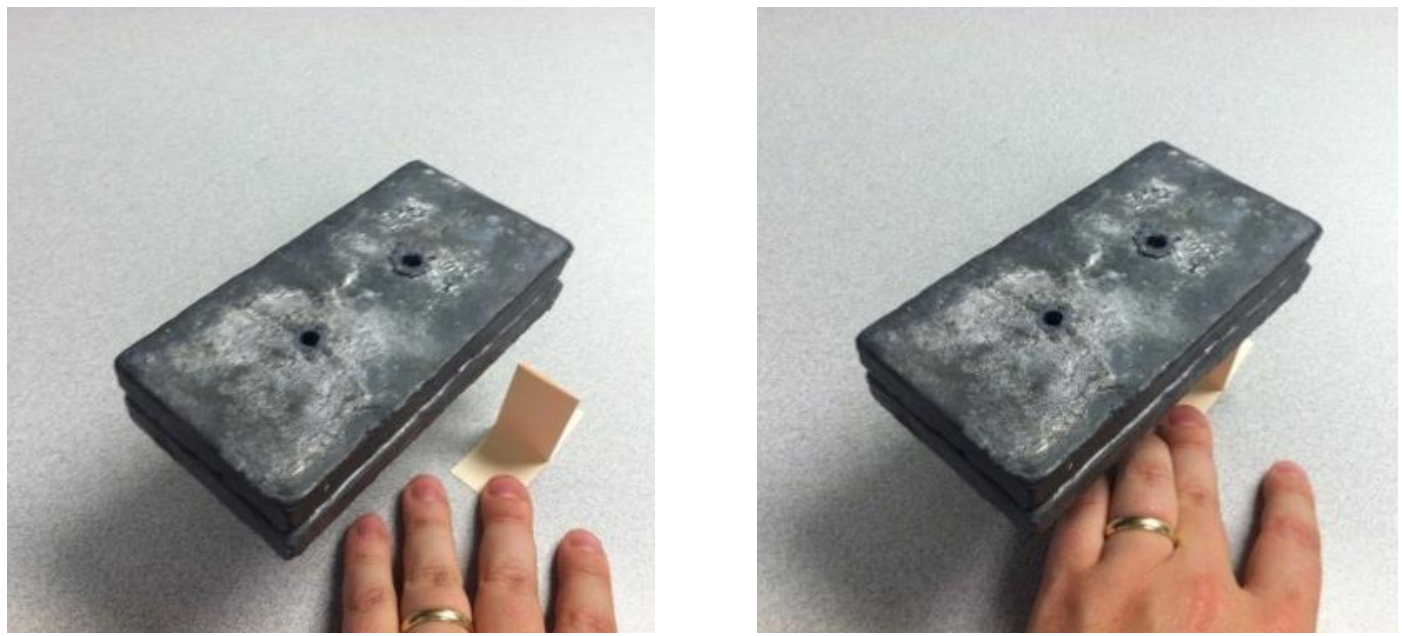

Fig. 3: Acceptance testing is performed by placing the masses on top of the widget and sliding a $1.75 "$ spacer underneath.

Figure 4 shows the winning designs from the past three years. The team responsible for the winning design from AY 2013-14 successfully delivered 100 widgets. While this volume is much less than what a manufacturer would consider mass production, it is considerably higher than the single prototype which is the typical focus of a capstone design project. 


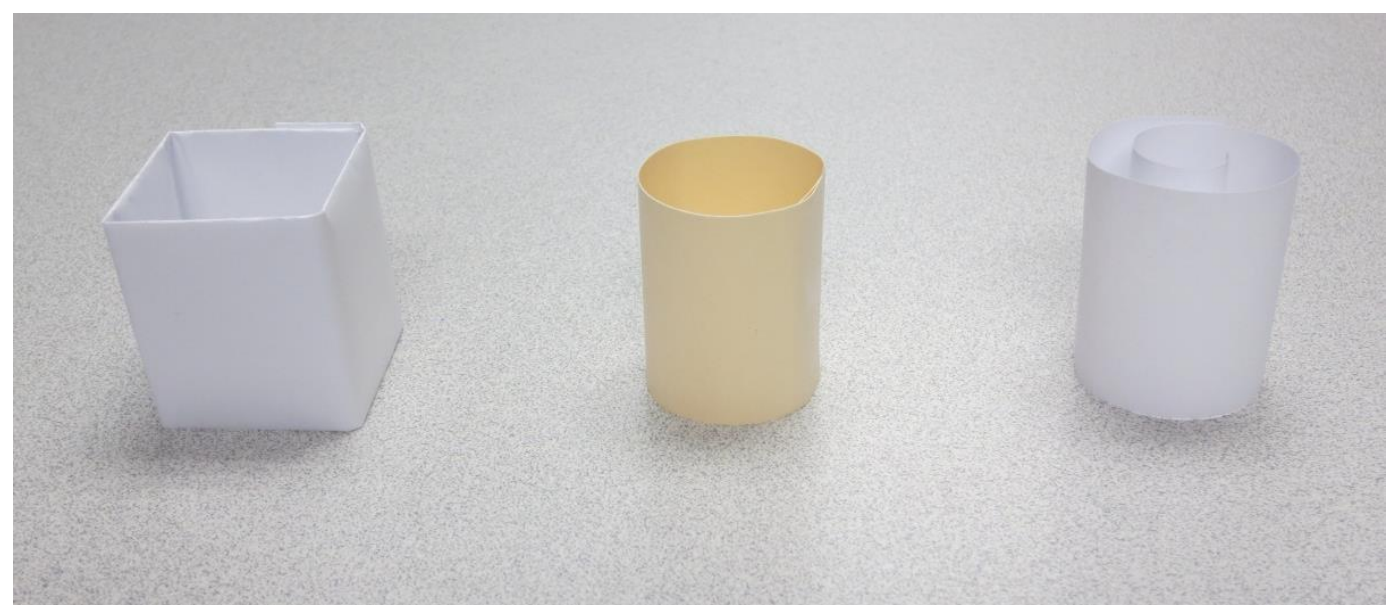

Fig. 4: Winning designs from AY 2011-12 (center), AY 2012-13 (left), and AY 2013-14 (right).

\section{Learning objectives, evaluation, and assessment}

At the end of this activity, students will be able to:

- Explain the importance of considering manufacturing processes throughout the product development process.

- Estimate fixed and variable manufacturing costs and iterate a design to reduce these costs.

- Differentiate between costs associated with development and with production.

- Iterate a prototype design to maximize earnings by reducing material and assembly costs.

- Explain the cost of poor quality.

Assessment of the learning objectives is carried out in two ways. First, a short quiz is given at the beginning of the period which covers the assigned reading from the textbook [1]. Second, a homework assignment (individual effort) is assigned to each student. In this assignment, the students are tasked with developing a spreadsheet table summarizing the results of the effort. The students are asked to reflect on the following:

- The impact of team size on overall performance (specifically, they are asked to list the factors relevant to the financial implications of team size and explain how their design exploited or mitigated these factors).

- The general strategy adopted in the design process.

- The primary constraints on team profitability.

- What the team could have done differently to improve their outcome. 
This activity provides a good opportunity for assessment of several ABET student outcomes; each is listed below and further discussed.

(c) An ability to design a system, component, or process to meet desired needs within realistic constraints such as economic, environmental, social, political, ethical, health and safety, manufacturability, and sustainability.

This activity provides numerous constraints including component size, product rating, limited product development time, limited manufacturing time, and fixed and variable costs associated with labor and materials. Assessment of this outcome can be based on whether or not teams were able to make a profit on their design.

\section{(d) An ability to function on multidisciplinary teams.}

Multidisciplinary teams are formed out of the cohort of engineering physics and optical engineering students in our class. Success in practice is only achieved through teamwork; by assigning a fixed cost per student for labor and keeping the manufacturing time short, all members of each team must work together to maximize their profit. By limiting development time, tasks such as concept generation/selection, prototype testing, and estimation for order commitment can be divided up among team members. Consensus building is ensured in that each team must select just one design to take into production. The individual reflection assignment can be used for assessment of teamwork.

(e) An ability to identify, formulate, and solve engineering problems.

In this activity, no guidance is given as to the approach they should take. Each team must work on their own to identify a feasible solution to problem, subject to the constraints which have been specified. Assessment of this outcome can be based on whether or not students were able to develop a functioning prototype.

\section{Future Improvements and Conclusion}

There are several areas in which this activity may be improved in the future. Each year several teams typically fail to yield positive earnings. We believe the principal contributing factors to this are poor teaming, poor quality control, and a failure to adequately estimate the number of widgets which can be produced in the manufacturing period. Self-selection of teams allows students to work with others with whom they comfortable. The disadvantage of this approach is that students tend to form teams with their friends rather than considering the impact of team size and make-up on the design. Next year, we will randomize teams (both in terms of team size as well as membership). With respect to quality control and issues with poor estimation, these are lessons which are worth learning by experience. The reflection assignment serves to reinforce the issue with those who do not succeed in the activity.

Another way in which this project could be improved is to alternate or cycle through several possible design goals. We have found that as students discuss their experiences with their friends who have not yet taken the course, the element of surprise is reduced (which effectively gives teams having members with prior knowledge of the project an advantage in product 
development). By changing the design objective, goal, and constraints between years, all teams will compete on a level playing field.

A short activity has been developed to present and reinforce the concepts of design for manufacturability. The activity is highly reusable; for example, by simply adjusting the designated costs or earning per widget each year, a previous year's winning design can be rendered ineffective given the new constraints. Further, this activity is not discipline-specific; we expect that it is well suited for students in all engineering fields.

\section{References}

[1] K. T. Ulrich and S. D. Eppinger, "Design for Manufacturability" in Product Design and Development, $5^{\text {th }}$ ed., ISBN 978-007340477, New York: McGraw-Hill, pp. 253-287, (2012).

[2] G. Boothroyd, P. Dewhurst, and W. A. Knight, Product Design for Manufacture and Assembly, $3^{\text {rd }}$ ed., Boca Raton: CRC Press, (2011).

[3] J. Bralla, Design for Manufacturability Handbook, $2^{\text {nd }}$ ed., ISBN 978-0070071391, New York: McGraw-Hill, (1999).

[4] M. B. Mehta and M. Angolia, "Holistic Consideration of Best Practices in Product Design, Quality, and Manufacturing Process Improvement through Design for Value," ASEE Annual Conference Proceedings, \#6927, (2013).

[5] R. V. Narang, "Introducing Design for Manufacturing and Assembly in the Manufacturing Technology Curriculum,” ASEE Annual Conference Proceedings, \#2248, (1996).

[6] B. L. Tuttle, "Teaching Design for Manufacturability: the Historical Events, the Current Event and the Future Events," ASEE Annual Conference Proceedings, \#2225, (1996).

[7] J. R. Golberg, "A Hands-On, Active Learning Approach to Increasing Manufacturing Knowledge in Engineering Students," ASEE Annual Conference Proceedings, \#6230, (2013).

[8] K. A. Smith, S. D. Sheppard, D. W. Johnson, R. T. Johnson, "Pedagogies of Engagement: Classroom-Based Practicies," Journal of Engineering Education, vol. 94, no. 1, pp. 87101, (2005). 